\title{
RADIOISOTOPE STUDIES OF CALCIUM METABOLISM IN THE LAYING HEN
}

\author{
Rosemary J. THOMAS \\ Unilever Research Laboratory, Colworth House, Sharnbrook, Bedford (Great-Britain)
}

\section{INTRODUCTION}

In order to learn more of the mechanism of eggshell formation by the domestic fowl and to discover factors possibly causing poor quality eggshells in modern light hybrid breeds of hen, we have studied calcium metabolism in individual hens by techniques of single or double labelling with radioisotopes in 24-hour blood sampling experiments. We set out to determine how the large demand for calcium is met at the precise time of shell calcification and to determine the contribution of the skeleton in relation to the times of ovulation, oviposition and feeding.

\section{EXPERIMENTAL}

The birds used were Shaver Starcross 288 hybrid fed on a normal complete layers ration containing 3 p. Ioo calcium (Ca) and a few Warren SSL hybrids that had $2 \mathrm{p}$. Ioo Ca diet.

The main experiments consisted of blood sampling at regular intervals during zo hours (or longer), including the period of calcification of an eggshell, to determine the changes in specific radioactivity of the isotopes of calcium that were used. A different bird was used for each experiment and at the conclusion of each the bird was killed so that its skeleton could be analyzed.

\section{METHODS}

The methods of using the isotopes were as follows:

I) ${ }^{45} \mathrm{CaCl}_{2}$ was administered to birds as an intraperitoneal injection of very high specific radioactivity (SRA) (approximately Io $\mu \mathrm{Ci} /$ bird/day in $\mathrm{I} \mathrm{ml}$ of $\mathrm{M} / \mathrm{roo} \mathrm{CaCl}_{2}$ ) for two weeks (BRow and MCCRACKEN, 1965). This method, as against that of putting the radioisotope in the daily ration for the same period was preferred only for its greater convenience and safety, avoiding the possibility of spillage from food troughs and scattering by the bird.

During this period, the hens remained with the rest of the flock. They were in single meta- 
bolic cages with a mechanism recording the time of the egg-laying, enabling us also to note the time in individual birds from oviposition to oviposition and the clutch pattern of each bird on experiment. After a day or two the birds became quite accustomed to handling, their laying was hardly affected, and it was in fact, a good preparation for the stress of the blood-sampling experiment itself.

2) ${ }^{45} \mathrm{CaCl}_{2}$ or ${ }^{47} \mathrm{CaCl}_{2}$ at a very high specific radio-activity in a small volume of physiologica 1 saline was infused into the right brachial vein of the bird at a known constant rate during the whole of a blood-sampling experiment.

3) Using ${ }^{45} \mathrm{Ca}$ for injections and ${ }^{47} \mathrm{Ca}$ for the infusion solution, birds could be injected for a fortnight and then infused with the ${ }^{47} \mathrm{Ca}$ during a blood sampling experiment.

4) ${ }^{45} \mathrm{Ca}$ or ${ }^{47} \mathrm{Ca}$ was mixed into the diet. It was given to several birds in the evening so that they only had radioactive calcium while calcifying an eggshell and they were killed the following day before the egg was laid.

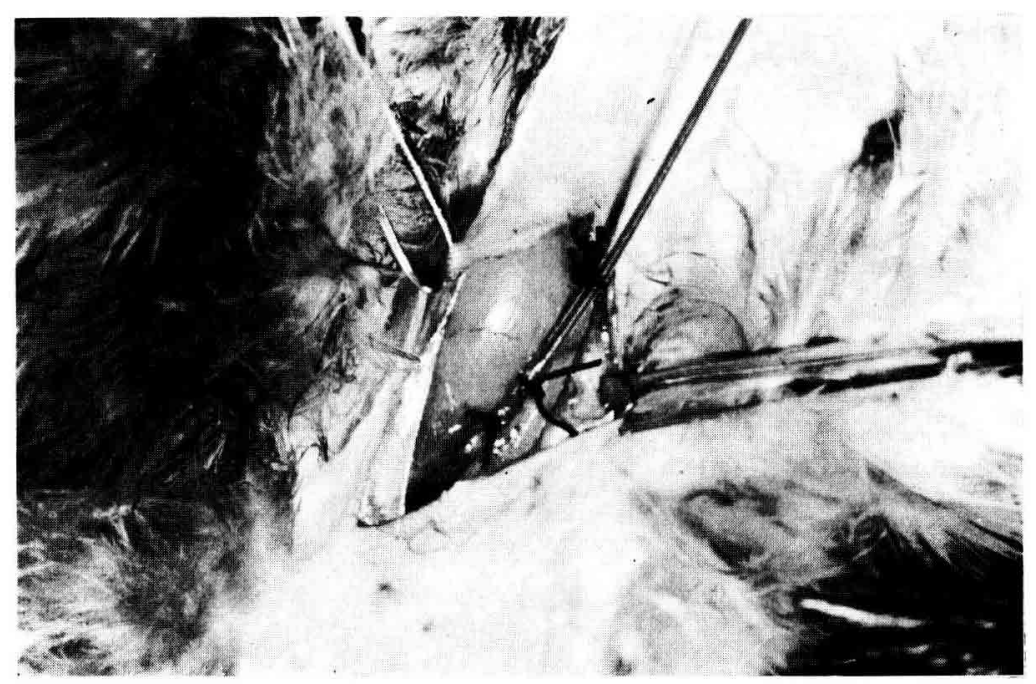

FIG. I. - The insertion of a venous catheter into the right brachial vein

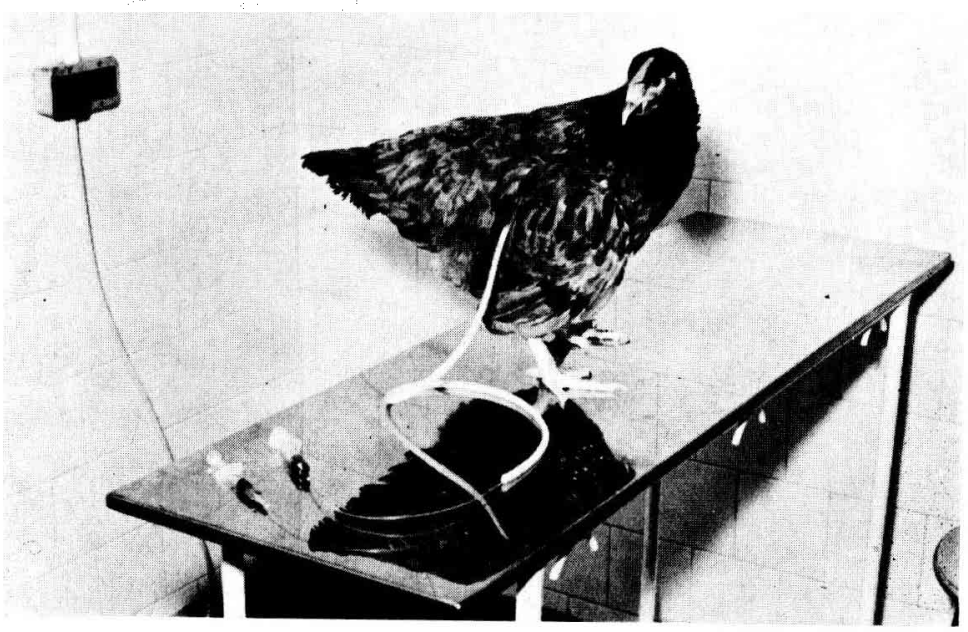

FIG. 2. - Catheterisation of the right brachial vein and artery complete. The catheters are enclosed in a protective druble lumen tube 
For the main experiment the catheterisation technique of HILL (I965) was used to insert catheters into the brachial vein and artery with only a local anæsthetic.

The operation (see fig. I) was either done a few days before the proposed day of the sampling experiment, allowing time for the bird to become used to the wing catheters, or else it was done on the day of the experiment itself at a time when the egg to be laid the following day would already be an hour or so in the oviduct. Once the egg had started on its passage through the oviduct, the stress of the operation and the overnight experiment rarely disturbed the normal passage of the egg to the uterus or its calcification.

The bird was placed in a small cage, and in early experiments inside a respiration chamber (for measurement of $\mathrm{CO}_{2}$ or ${ }^{14} \mathrm{CO}_{2}$ ) and the ends of the catheters brought out through an aperture in the side wall. To protect the catheters from the bird and prevent her seeing the blood samples withdrawn, the catheters were threaded through a thicker double lumen sheath tube. (see fig. 2).

For infusion experiments, the infusion pump was attached to the venous catheter. At intervals, $2 \mathrm{ml}$ blood samples were withdrawn from the arterial catheter. Total plasma calcium and specific radioactivity (SRA) of ${ }^{47} \mathrm{Ca}$ and $/$ or ${ }^{45} \mathrm{Ca}$ were measured in plasma calcium.

The SRA ${ }^{47} \mathrm{Ca}$ and ${ }^{45} \mathrm{Ca}$ was measured in the eggshell produced and in samples of cortical and medullary bone of the femur and tibia which were removed from the bird when she was killed at the end of the experiment. The results are a summary from 35 experiments but all the examples given are of individual successful experiments.

\section{RESUITS}

FIG. 3. - The specific radioactivity of and infused radioisotopes of calcium during eggshell calcification ( $\mathrm{FC} 27$ ). Shaver 288 aged 47 weeks.

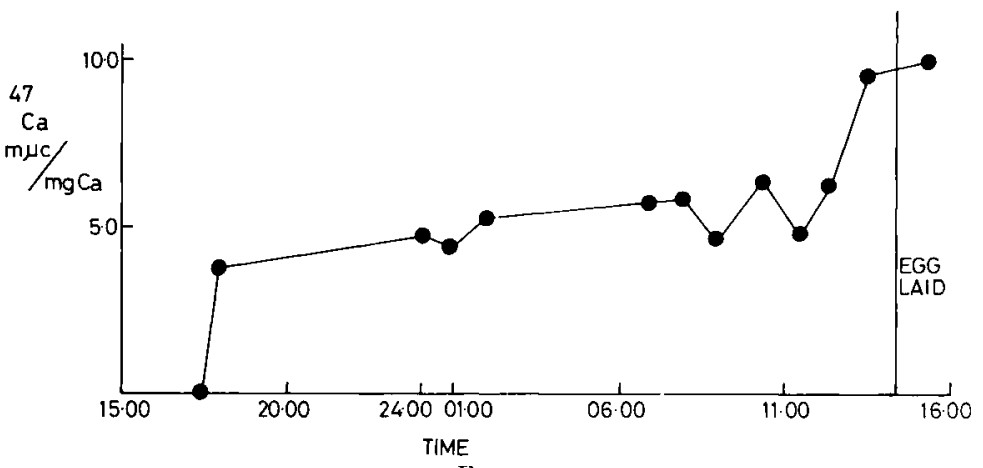

FIG. 3

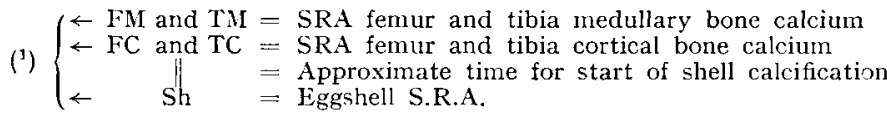

Fig. 3 shows the results obtained from an infusion experiment. An hour or so after the start of the infusion the level of the infused radioisotope in the blood reached a plateau. Towards the end of the experiment just before an egg was laid, the level rose quite sharply. The plateau in the specific radioactivity indicates a state of equilibrium presumably with the calcium of the body fluids. A true plateau was seldom achieved, possibly indicating a further slow equilibration with another calcium pool, such as of medullary bone.

Knowing the rate at which the infused isotope was entering the blood pool from

(1) Legends for all the figures (Note des éditeurs). 
the pump and the level of the isotope in the plasma calcium, the rate at which calcium was entering and leaving the pool could be calculated.

Entry rate of calcium into total plasma calcium pool $=$

$$
=\frac{\text { Infusion rate } \mathrm{m} \mu \mathrm{c}{ }^{47} \mathrm{Ca} / \mathrm{min}}{\text { SRA Ca in plasma }{ }^{47} \mathrm{Ca} \mathrm{m} \mu \mathrm{c} / \mathrm{mg}}=y \mathrm{mg} \mathrm{Ca} / \mathrm{min}
$$

The ${ }^{4} \mathrm{Ca}$ levels we have found such as in the experiment in Fig. 3 show that the plasma calcium entry rate remained steady until an hour or so before the egg was laid. At this time the ${ }^{47} \mathrm{Ca}$ SRA rose sharply, that is the entry rate of plasma Ca fell, and this must mean that calcification was concluded although the egg was not necessarily laid immediately and might be delayed, at least under the conditions of this experiment, by several hours. The steady plateau was a consistent result and another example is given in fig. 4 which also demonstrates how unaffected it was by periods of feeding.

FIG. 4. - The specific radioactivity of plasma calcium during eggshell calcification (FC 72). Warren SSL Aged 66 weeks. ${ }^{45} \mathrm{Ca}$ injected daily for one fortnight previously. ${ }^{47} \mathrm{Ca}$ infused at a constant rate during experiment).

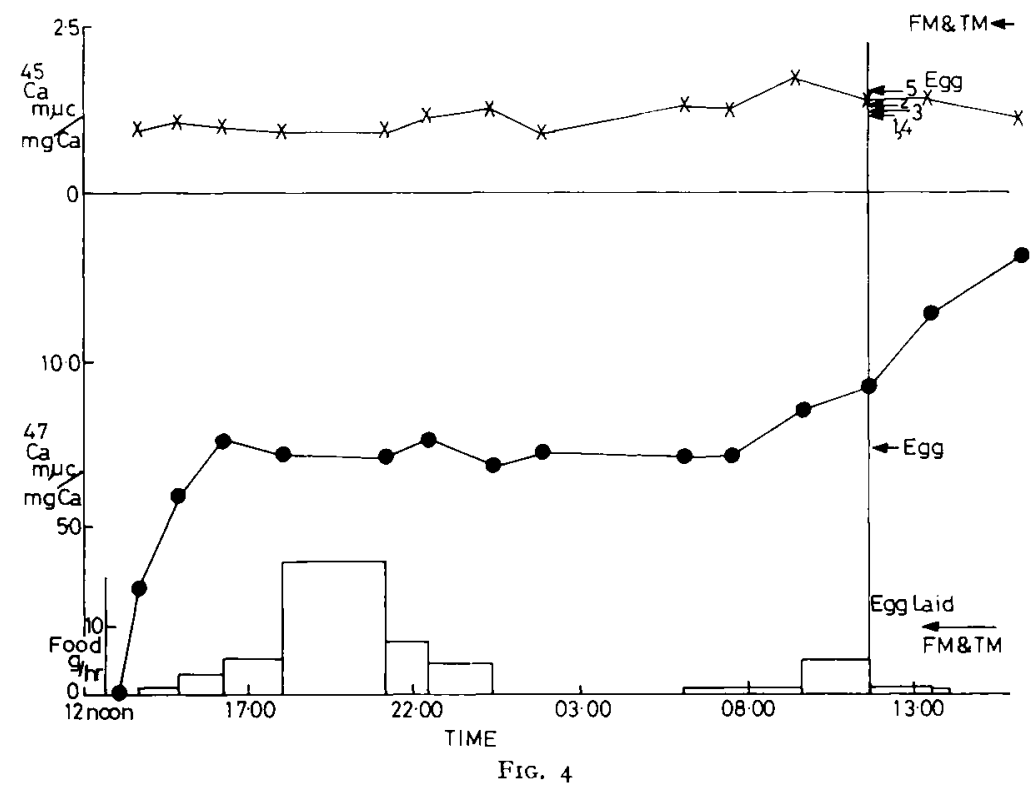

The specific radioactivity of $\mathrm{Ca}$ found in the shell of an egg laid in such an experiment matched that of the calcium in the blood, showing that the assumptions we made in the calculation of entry rates are justifiable.

To calcify an average eggshell in 15 to 16 hours it has been calculated that calcium ions must be withdrawn from the blood at a rate of $100-150 \mathrm{mg} / \mathrm{hour}$ during that period. The entry rates calculated from these isotope dilutions gave a figure of 2 or $3 \mathrm{mg} \mathrm{Ca} / \mathrm{min}$ or $120-\mathrm{I} 80 \mathrm{mg} / \mathrm{hr}$.

Infusion experiments done with sister birds during a similar period but without 
an egg in the shell gland did not give any uniform picture or any smooth equilibration plateau.

In longer experiments, lasting $30-36$ hours, the period between two calcifications in individual hens was observed.

FIG. 5. - The specific radioactivity of plasma calcium during two successive periods of shell calcification $\left({ }^{45} \mathrm{Ca}\right.$ infusion). Shaver 288 Aged 25 weeks.

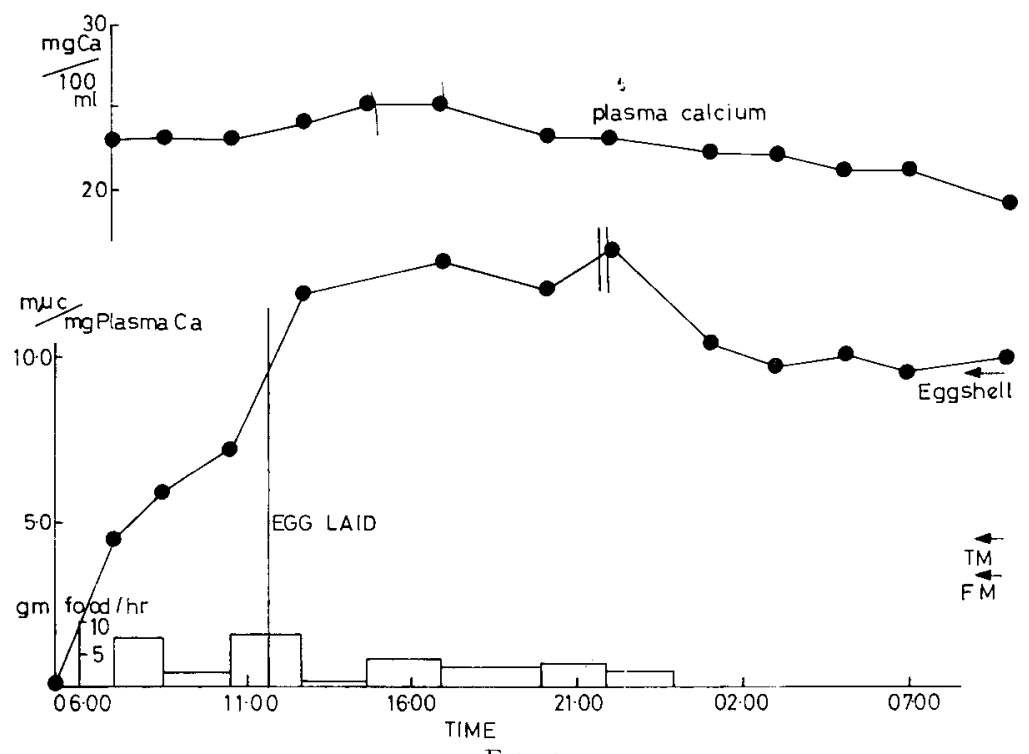

FIG. 5

A plateau of the specific activity was reached at a high level after the first oviposition and the levels fell again to a new plateau at about the expected time for calcification to begin.

The average entry rate between calcifications was $1.06 \mathrm{mg} \mathrm{Ca} / \mathrm{min}$ rising to I.34 $\mathrm{mg} \mathrm{Ca} / \mathrm{min}$ during the second shell forming. The second plateau could however, have been affected by the infused isotope re-entering from bone pools during the second calcification so the true entry would be higher than indicated directly.

Short infusions were also done on young birds in the few weeks before the flock came into lay.

Frg. 6. - The specific radioactivity of plasma calcium during an infusion of ${ }^{45} \mathrm{Ca}$.

Shaver 288 Aged I8-20 weeks

There were steady rises in SRA ${ }^{45} \mathrm{Ca}$ showing possibly slow equilibration with pools beyond that of blood calcium such as of medullary bone.

When infusion of ${ }^{47} \mathrm{Ca}$ was combined with a preparatory period of feeding or injection of ${ }^{45} \mathrm{Ca}$, blood, bone and shell samples contained both radioisotopes. The changing SRA of the ${ }^{47} \mathrm{Ca}$ (infused) gave the time-scale of the calcification and a measure of the entry rate of total plasma calcium and the (previously injected) isotope 
${ }^{46} \mathrm{Ca}$, which during the experiment could come only from stored body sources, gave a measure of the mobilisation of the skeletal calcium for calcification (see fig. 4).

The ${ }^{45} \mathrm{Ca}$ level in the plasma must be affected by the rate of turnover of the total plasma calcium. Because ${ }^{47} \mathrm{Ca}$ and ${ }^{45} \mathrm{Ca}$ are both labelling the total plasma calcium, the entry rate calculated from the $\mathrm{Ca}-47$ data can be applied as follows.

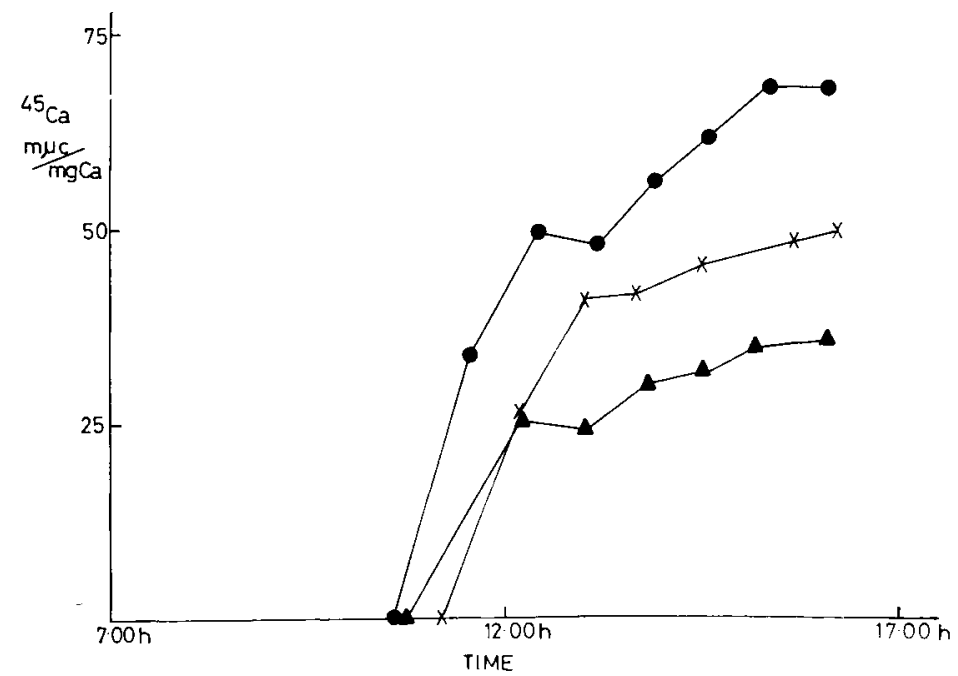

FIG. 6 (Sce text)

Entry rate of calcium into total plasma calcium pool $=$

$$
=\frac{\text { Infusion rate } \mathrm{m} \mu \mathrm{c}{ }^{47} \mathrm{Ca} / \mathrm{min}}{\mathrm{SRA}^{47} \mathrm{Ca} \text { in plasma Ca } \mathrm{m} \mu \mathrm{c} / \mathrm{mg} \mathrm{Ca}}=y \mathrm{mg} / \mathrm{Ca} / \mathrm{min}
$$

Infusion rate of ${ }^{55} \mathrm{Ca}$ from mobilisable bone pool $(\mathrm{m} \mu \mathrm{c} / \mathrm{min})=$

$==$ Entry rate $(y \mathrm{mg} / \mathrm{mn}) \times \mathrm{SRA}^{45} \mathrm{Ca}$ in plasma Ca $\mathrm{m} \mu \mathrm{c} / \mathrm{mg} \mathrm{Ca}$

The changing values in $\mathrm{m} \mu \mathrm{c} / \mathrm{min}$ give a measure of how the mobilisation is changing during the period of one experiment.

FIG. 7, 8, 9. - a) Entry rate of total plasma calcium. b) Entry of ${ }^{45} \mathrm{Ca}$ into plasma Ca pool

If we had an exact value for the SRA of ${ }^{45} \mathrm{Ca}$ in the bone pool at the beginning of the experiment the figures could be converted into absolute figures for the mobilisation in $\mathrm{mg} / \mathrm{min}$ of skeletal calcium.

At the end of the calcification when the ${ }^{77} \mathrm{Ca}$ level rose sharply, in several birds a small peak in ${ }^{45} \mathrm{Ca}$ was also observed. Taken alone this might be interpreted as an increased mobilisation from a skeletal source but in relation to the great fall in turnover of plasma calcium, it appears to be an overshoot, the bone calcium continuing to be mobilised at the same rate for a short time before that also lessens.

In all of these experiments the ${ }^{45} \mathrm{Ca}$ SRA was remarkably constant during shell 
calcification. In some birds there was a gradual rise in the early stages but for the majority, the skeletal pool appeared to contribute at a steady rate for the I5 or I6 hour period.
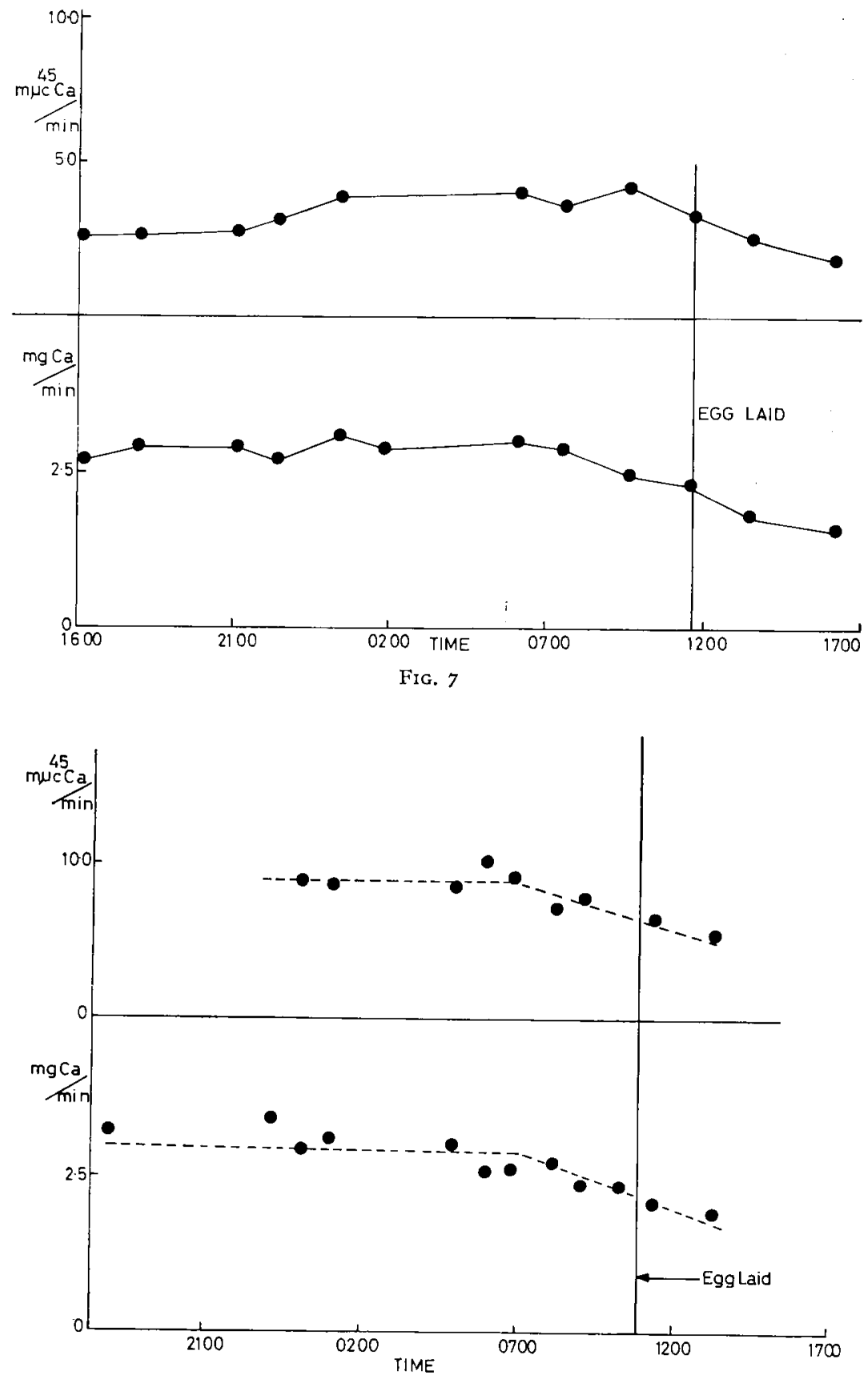

Fig. 8 (See text) 


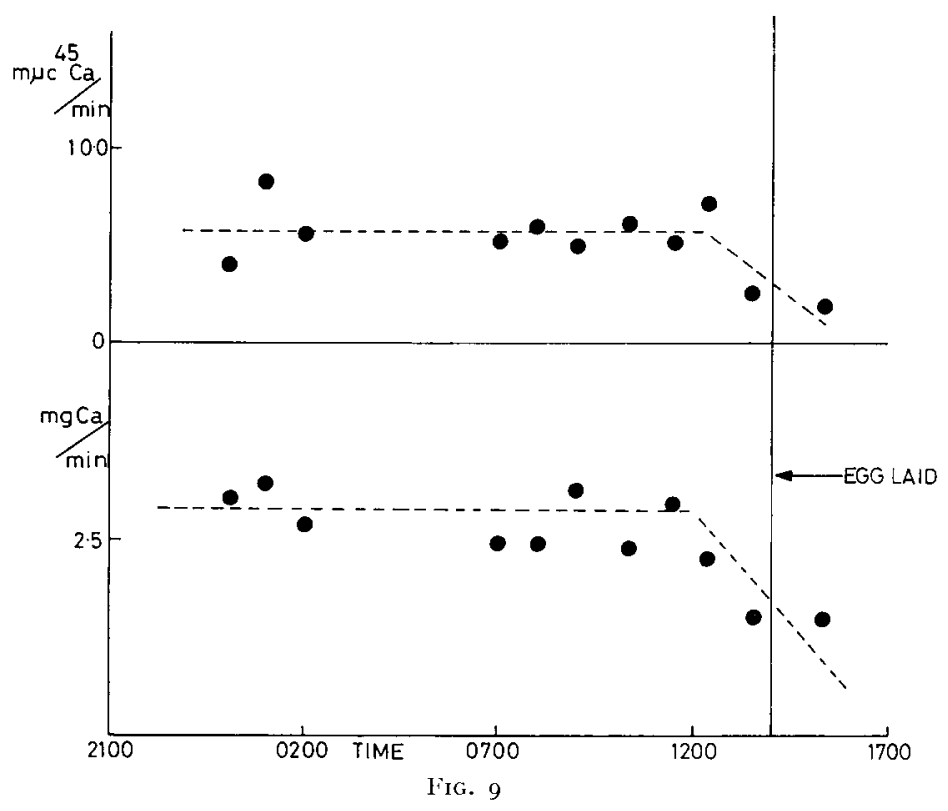

To compare the results with the overall entry rate of plasma $\mathrm{Ca}$ obtained from the ${ }^{47} \mathrm{Ca}$ data and to enable comparison between birds, the entry rates were calculated as values relative to those at the time of oviposition (CHAdwick and Shrimpton, 1968). (See fig. Io).

FIG. Io. - Table of calculated rates of entry of calcium into the plasma calcium pool

Several experiments were done where the skeleton was labelled with ${ }^{45} \mathrm{Ca}$ by injection but no infusion was given during the blood-sampling period. These provided the same picture of SRA of ${ }^{45} \mathrm{Ca}$ from the skeleton in relation to the period of shell formation. Several of these experiments were extended to 30 hours altogether to include parts of two successive shell calcifications and show more clearly the skeletal contribution to the plasma calcium pool when the bird was not calcifying an eggshell. (See fig. II and I2).

FIG. II-I2. - The specific radioactivity of plasma calcium during two successive periods of shell formation ( ${ }^{15} \mathrm{Ca}$ previously injected). Shaver 288 Aged 28 weeks. Shaver 288 Aged $3 \mathrm{I}$ weeks.

The changes in SRA of ${ }^{45} \mathrm{Ca}$ were not dramatic. Bearing in mind the change in turnover of the total plasma calcium, the skeletal contribution must have been greatly increased during shell calcification. It was noticeable that the overall fall in SRA ${ }^{45} \mathrm{Ca}$ even during the whole period was quite small.

The SRA of both infused and pre-injected isotopes found in the blood plasma corresponded with the SRA of the eggshell produced and the shell could be dissolved 


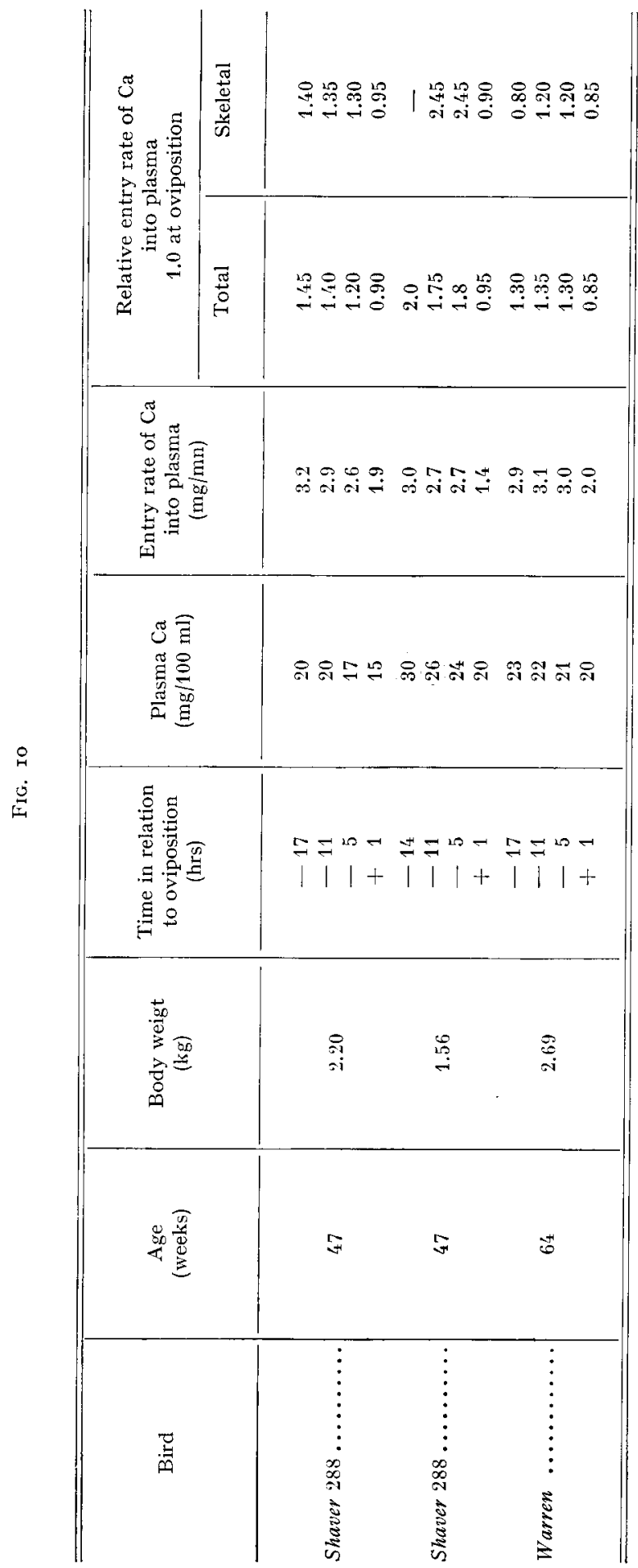


away in 5 or 6 layers which corresponded roughly with the levels found in the blood during calcification.

When an injected bird is killed at the end of a sampling experiment the SRA of the medullary bone calcium of femur and tibia are similar and about Io times as high as levels in the cortical bone.

The medullary SRA levels were sometimes similar to the SRAs of blood calcium

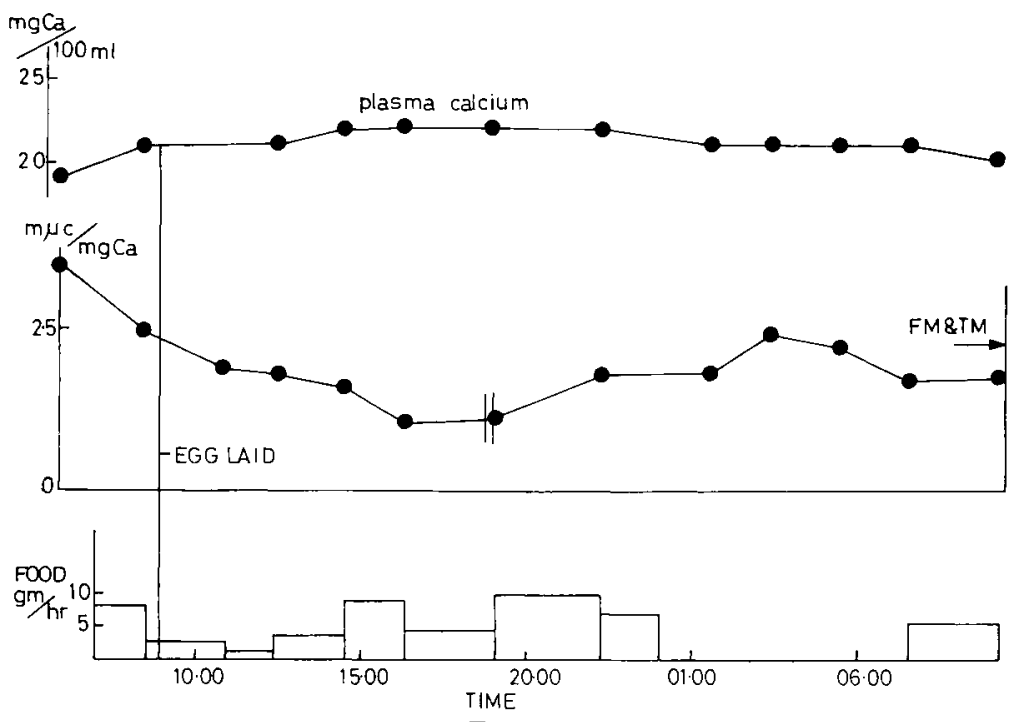

FIG. II

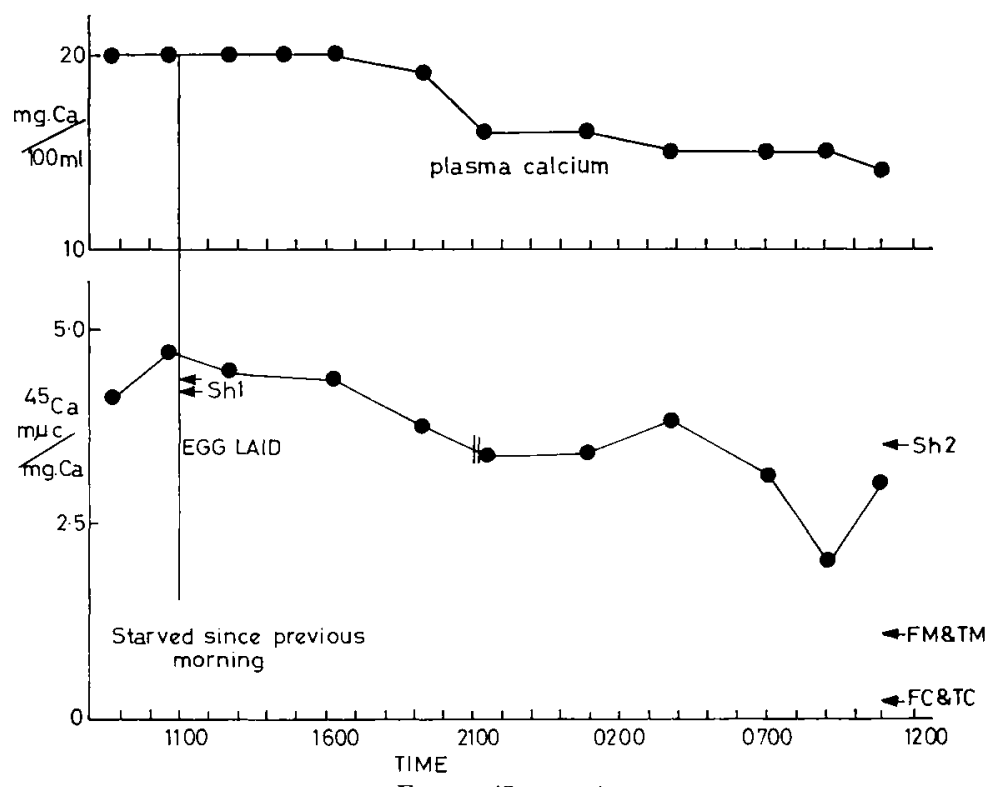

FIG. I2 (See text) 
but in fact unpredictable, they might be a little above or below the blood levels during the experiment.

When a bird was not killed until a week or ten days after the end of a course of injections the labelling of the eggs fell and the SRA of Ca of medullary bone at the end of the period was low and approached the level in the cortical bone; that is to say, the labelling of the cortical bone fell slowly compared to the labelling of the medullary bone.

FIG. I3. - The specific radioactivity of eggshells produced after a course of ${ }^{45} \mathrm{Ca}$ injections

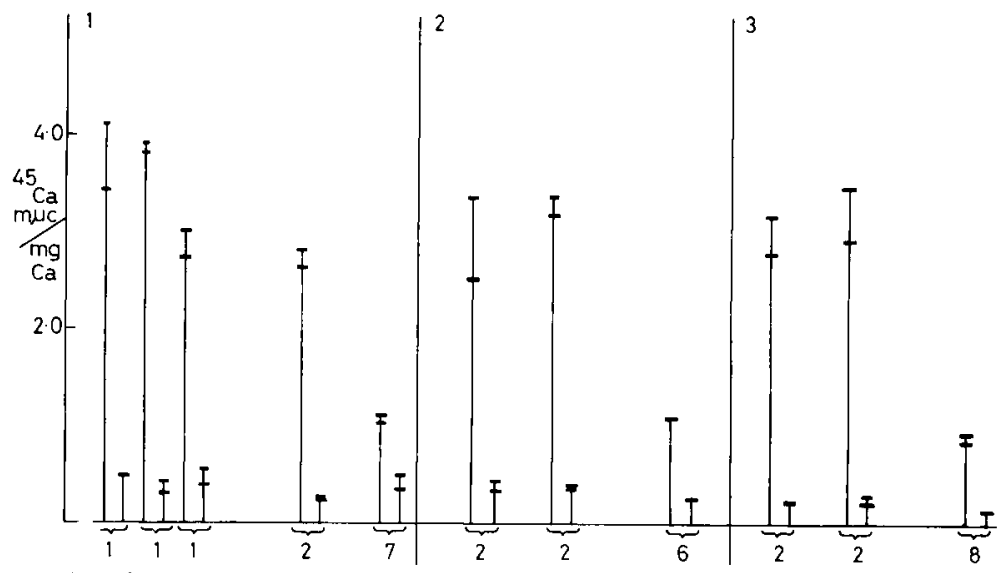

No. of days between

last ${ }^{45} \mathrm{Ca}$ injection and killing of bird

FIG. I3

Exp. 3I Group I. Thornber 606 Aged 32 weeks

Exp. 40 Group 2. Shaver 288 Aged 44 weeks

Exp. 34 Group 3. Shaver 288 Aged 63 weeks

FIG. I4. - The specific radioactivity of medullary bone and cortical bone after a course of ${ }^{45} \mathrm{Ca}$ injections

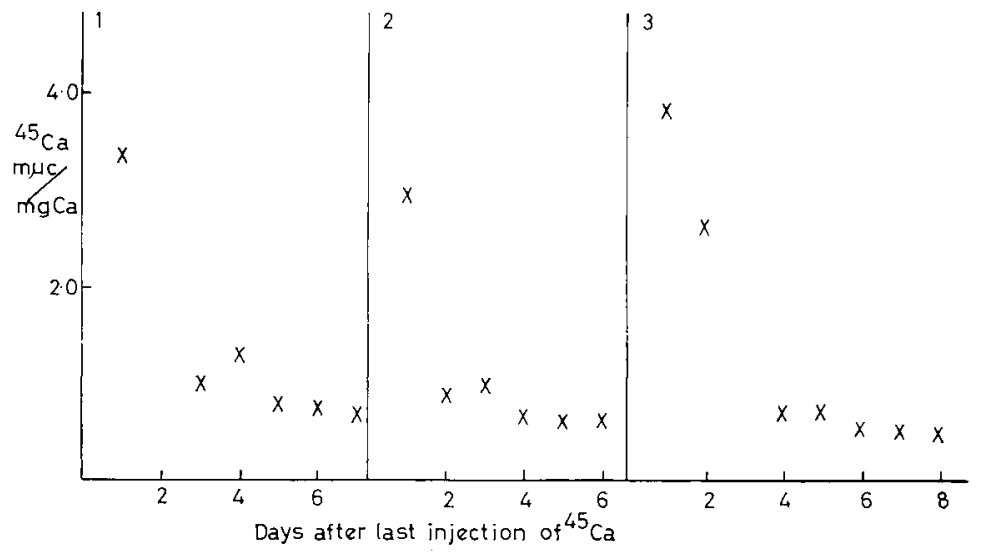

FIG. I4 
In looking at the results of labelling the skeleton or infusing a radioisotope we have to this point assumed that while bone is being mobilised to supply calcium, it is not at the same time being replenished by incoming dietary calcium which if going into the same bone pool, would dilute the $\mathrm{Ca}-45$ label so modifying the calculated relative entry rates of ${ }^{45} \mathrm{Ca}$ in $\mathrm{m} \mu \mathrm{c} / \mathrm{min}$. At the end of calcification, if dietary calcium is then taken up by bone we would expect to see the ${ }^{45} \mathrm{Ca}$ level in the blood fall, before remobilisation for another eggshell, and this fall was observed although it was generally rather gradual. However we also found that some of our infused isotope had entered the medullary bone even when a bird was killed immediately after she had laid an egg.

To find out therefore, whether bone was being actively replaced even during shell calcification, some birds were given a radioactive feed but only during the time a shell was being calcified. The food was given in the evening and the birds killed the following morning an hour or so before the expected time of egg-laying to eliminate the possibility of calcification ending a time before the egg was laid.

FIG. I5. - The labelling of bone and eggshell from feeding radiocalcium in the ration

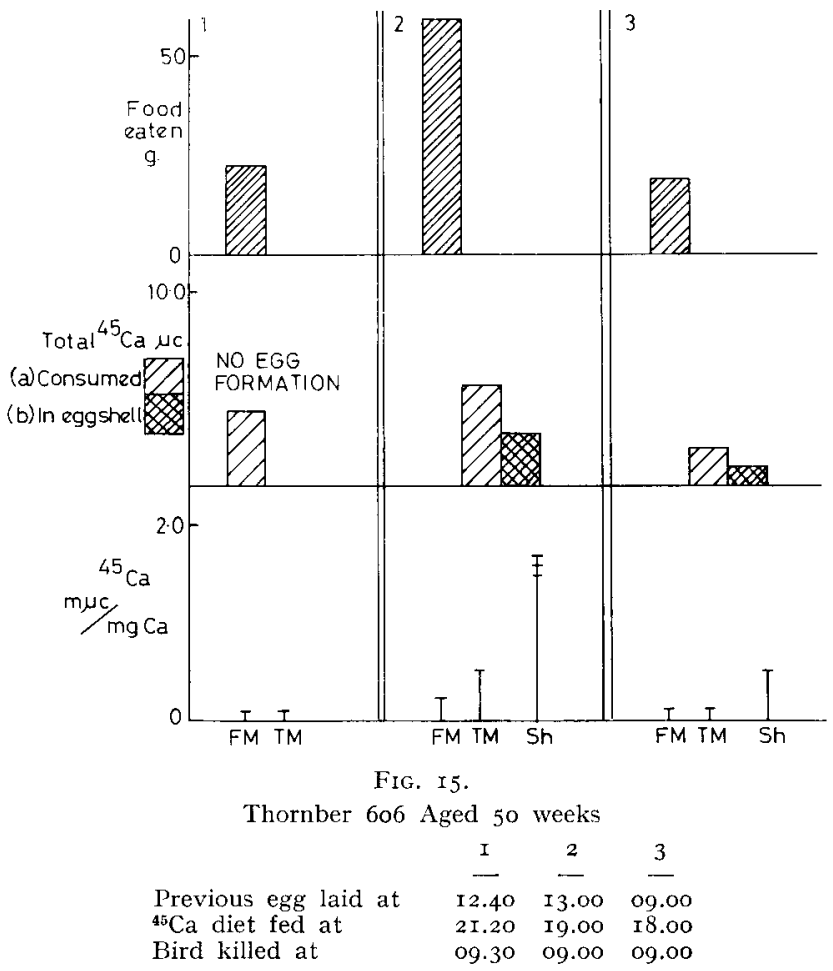

These and other experiments have shown that the labelling of bone is very little affected by whether the labelled ration was fed during or in the absence of shell calcification. When blood samples were taken during feeding experiments it was found that ${ }^{45} \mathrm{Ca}$ very soon appeared in the blood and if no shell was being formed, 
SRA ${ }^{45} \mathrm{Ca}$ soared rapidly. At the end of the experiments small amounts were found in the medullary bone.

\section{CONCI,USION}

It must be pointed out that the complexity of the metabolic situation of calcium in the laying hen prevents the proposal of a single hypothesis from these experiments. Although the radioisotope techniques provide us with a means of studying a dynamic system, many of the conclusions are necessarily tentative because of the limitations inherent in incomplete data. For instance, we have measured SRA of ${ }^{45} \mathrm{Ca}$ in the medullary bone of the femur and tibia but these are not usually the same and it cannot be assumed that all the medullary bone in the skeleton has the same activity, that it is all equally readily available or that there are not several levels or pools in all medullary bone. Therefore we cannot calculate from the experiments we have done so far, the actual contribution of the skeleton to plasma calcium with only two samples at the end of the experiment when it has already been drawn upon for the calcification of the experimental egg.

The SRA cannot be obtained from sister birds treated identically; individual birds do vary in the amount of radioactivity incorporated into their bone and the SRA is bound also to be affected by the number of eggs laid during the injection period.

There are four main points to note from the results of these experiments.

I. The entry rate of calcium into the total plasma calcium pool changes to a higher but steady level during the period of eggshell calcification.

2. The specific radioactivity in the blood calcium of a pre-injected isotope which must be stored in the skeleton is remarkably steady for a period which is sometimes as long as 30 hours. The slight increase generally observed in the early stages of a shell calcification and the increased turnover of blood calcium shows that skeletal calcium is being mobilised much faster during this time but there are no pronounced changes for most of the calcification period, whether the bird is starved or fed.

3. From infusion experiments and from feeding experiments we have found that medullary bone is exchanging with calcium from the plasma pool during the time the shell gland is avidly taking it up for the eggshell. We cannot estimate from these experiments the quantitative significance of this or how it affects the calculations of entry of radio calcium from the bone. As mentioned earlier, there was not always a plateau in the SRA of an infused isotope into the plasma calcium pools indicating incomplete equilibration with secondary pools, presumably in the medullary bone.

4. The fourth interesting point concerns the role of cortical bone in the system. of exchanging pools of calcium. It becomes labelled during a period of feeding or injection and the SRA of ${ }^{45} \mathrm{Ca}$ after Io days or a fortnight is about $\mathrm{I} / \mathrm{I}$ o of that of the medullary calcium. If injections are discontinued and the bird continues to lay eggs: the SRA of the medullary calcium drops relatively sharply and approaches that of the cortical bone which falls only gradually.

The work was aiming to find ultimately possible reasons for the fall in egg quality towards the end of the 1 aying year so we were looking for variations between breeds. 
and different ages of hens. We found it almost impossible to compare results successfully because each experiment is so individual in that the hens had laid different numbers of eggs prior to the experiment and so on. Comparisons would be more feasible if larger numbers of hens could be dealt with, using possibly layers of the shell as indicators of the course of mobilisation in pre-injected hens of calcium into the blood pool rather than this blood-sampling technique. Following TyLER (I954) we are now working on a technique for making autoradiographs of eggshell sections which would give us this information.

Blood-sampling experiments might be further employed, to study, for instance, the effects of parathyroid or oestrogens on bone mobilisation, and more direct studies on the plasma calcium and its carriers would go far to clarifying the situation. HuRWITz is already working on this (HURWITZ, I968) and we have also done a little preparatory work using electrophoresis and gel filtration methods combined with isotopic labelling. One of the limiting factors in shell calcification could be a binding blood protein that equilibrates relatively slowly, (as has been found by HuRwiTz) which could prevent optimal uptake of Ca by the shell gland. Related to the limitation of Ca supply is the possible limitation of the length of time spent by the egg in the shell gland of high production birds which may lay every 24 hours for several weeks.

\section{SUMMARY}

The supply of blood calcium to the shell gland to meet the large demand for the calcification of an eggshell could, at any one time, come entirely from calcium from the diet or from the skeleton or from any ratio of the two.

To study this supply in relation to the time of ovulation, oviposition and feeding, 24-hour blood sampling experiments were carried out using single or double labelling with radioisotopes of calcium. Autoradiographs of the shells are currently being examined.

${ }^{45} \mathrm{Ca}$ was equilibrated with skeletal $\mathrm{Ca}$ by daily intraperitoneal injections of $10 \mu \mathrm{Ci}$ and ${ }^{47} \mathrm{Ca}$ was equilibrated with plasma Ca during the studied period of shell formation by continuous infusion of a solution into the brachial vein. Blood samples were withdrawn from the brachial artery.

The entry rates of calcium into the total plasma calcium pool were calculated. They were increased during shell calcification in spite of only small variations in plasma calcium concentration.

The mobilisation of skeletal calcium was increased during shell calcification and its entry into the plasma pool varied independently of that of total calcium. There was no consistent pattern relating maximum skeletal mobilisation to the times of feeding and oviposition but variation was remarkably small during the period of shell calcification.

There was a small uptake of plasma calcium into medullary bone during the time of shell calcification.

\section{RÉSUMÉ}

\section{ÉTUDES RADIOISOTOPIQUES DU MÉTABOLISME CALCIQUE CHEZ LA PONDEUSE}

Pour assurer la forte demande de l'utérus, le calcium sanguin provient soit directement du calcium alimentaire, soit des réserves squelettiques ou des deux.

Afin d'étudier cet apport calcique vers le sang en fonction de l'heure d'ovulation, d'oviposition et d'alimentation, des prélèvements de sang ont été effectués durant des périodes de $24 \mathrm{~h}$ après un simple ou double marquage avec les deux radioisotopes du calcium. Les coquilles d'œuf ont été examinées par autoradiographie. 
On a équilibré le squelette avec du ${ }^{45} \mathrm{Ca}$ par des injections journalières par voie intrapéritonéale de Io $\mu \mathrm{Ci}$ et on a équilibré le sang par infusion continue de ${ }^{47} \mathrm{Ca}$ dans la veine brachiale pendant les périodes d'étude de formation de la coquille. Les échantillons de sang ont été prélevés dans l'artère brachiale.

Les entrées de calcium dans le pool calcique plasmatique total ont été calculées. Elles augmentent durant la calcification malgré les faibles variations de la calcémie.

La mobilisation du calcium squelettique augmente durant la calcification et son entrée dans le pool calcique varie indépendamment de celle du calcium total. Il n'y a aucune loi reliant la mobilisation maximale du calcium squelettique à l'heure du repas ou de l'oviposition mais la variation est très faible durant la calcification de la coquille.

Il y a une légère entrée de calcium plasmatique dans l'os médullaire durant la calcification de la coquille.

\section{REFERENCES}

Brown W. O., MCCRAcken K. J., I965. The partition of certain mineral nutrients in the colostomised laying pullets and the determination of facal and endogenous calcium and phosphorus excretion by an isotopic dilution method. J. Agric. Sci., 64, 305 .

Chadwick R. J., Shrimpton D. H., I968. Mobilization of calcium for eggshell formation in the domestic hen. Proc. Nutr. Soc., 27, 4 A.

Hil. K. J., I965. Personal communication.

Hurwitz S., 1968. Calcium exchange in plasma of the fowl. Biochim. Biophys. Acta, 156, $38 \mathrm{~g}$.

Tyler C., 1954. J. Sci. Food. Agric., 5, 335. 